\title{
Research Article \\ Effect of Construction Method on Shear Lag in Prestressed Concrete Box Girders
}

\author{
Shi-Jun Zhou' ${ }^{1,2}$ \\ ${ }^{1}$ School of Civil Engineering, Chongqing University, 174 Shazheng Road, Chongqing 400030, China \\ ${ }^{2}$ Key Laboratory of New Technology for Construction of Cities in Mountain Area, Ministry of Education, \\ Chongqing University, Chongqing 400030, China \\ Correspondence should be addressed to Shi-Jun Zhou, sjzhou8@163.com
}

Received 27 June 2012; Revised 30 August 2012; Accepted 30 August 2012

Academic Editor: Zheng-Guang Wu

Copyright (C) 2012 Shi-Jun Zhou. This is an open access article distributed under the Creative Commons Attribution License, which permits unrestricted use, distribution, and reproduction in any medium, provided the original work is properly cited.

\begin{abstract}
Most of the previous researches conducted on shear lag of box girders were only concerned about simple types of structures, such as simply supported and cantilever beams. The structural systems concerned in these previous researches were considered as determined and unchangeable. In this paper, a finite element method considering shear lag and creep of concrete was presented to analyze the effect of dynamic construction process on shear lag in different types of concrete box-girder bridges. The shear lag effect of the three types of a two-span continuous concrete beam classified by construction methods was analyzed in detail according to construction process. Also, a three-span prestressed concrete box-girder bridge was analyzed according to the actual construction process. The shear lag coefficients and stresses on cross sections along the beam including shear lag were obtained. The different construction methods, the changes of structural system with the construction process, the changes of loading and boundary conditions with the construction process and time, the prestressing, and creep were all imitated in the calculations. From comparisons between the results for beams using different construction methods, useful conclusions were made.
\end{abstract}

\section{Introduction}

The shear lag effect is one of the most important mechanical characteristics of box girders. Numerous research efforts on analytical method of shear lag effect of thin-walled box girders have been made for many decades, and much progress has been achieved. However, most of previous researchers were concentrated more towards simply supported, cantilever as well as determined and unchangeable structural types of beams [1-16]; whereas the dynamic changes of structural system with construction process as well as effect of creep of concrete on shear lag of box girders were excluded. 
Recently, some researchers have attempted to analyze the effect of shear lag on box girders using finite beam element, where one shear-lag degree of freedom (DOF) at each node of the beam element was adopted $[8,9,16]$. With the advantage of simplification and convenience, the method could be appropriate for analyzing the effect of shear-lag of a box girder. However, this element includes only one shear-lag DOF at each node which is not suitable for all types of support and load conditions. Considering that the previous beam element with one shear lag DOF at each node cannot satisfy the boundary condition while $\psi^{\prime}=0$ (where $\psi$ is maximum difference of angular rotation due to shear deformation) and the continuity condition under concentrated bending moments, a coefficient matrix method (CMM) has been proposed by the author $[17,18]$. In this method, it is assumed that shear lag only changes the distribution of normal stresses inside the cross-section, but wouldn't change the longitudinal distribution of internal forces along the girder. Two shear-lag DOFs at each node of the element were used for the shear lag analysis under different boundary conditions and continuity conditions. The shear lag coefficients of box girders could be easily obtained by using the CMM. However, the interaction of bending and shear lag deformation was not considered in the CMM. Therefore, the effect of shear lag on internal forces and vertical deformation of box girders cannot be analyzed by using the CMM.

In this paper, a finite element method considering interaction of bending and shear lag deformation was used to analyze the effect of construction process and creep on shear lag in concrete box girders. The changes of structural system with the construction process, the changes of loading and boundary conditions with the construction process and time, the prestressing, and creep are all imitated in the calculations.

\section{Finite Element Method for Calculation of Shear Lag Effect}

A new beam element considering the shear lag effect in a box girder was proposed by the author [19] to analyze the effect of shear lag on box-girders. The element nodal displacement vector $\{\delta\}$ and element nodal force vector $\{F\}$ could be expressed as

$$
\begin{gathered}
\{\delta\}=\left[\begin{array}{llllllll}
v_{i} & \theta_{i} & \psi_{i} & \psi_{i}^{\prime} & v_{j} & \theta_{j} & \psi_{j} & \psi_{j}^{\prime}
\end{array}\right]^{T}, \\
\{F\}=\left[\begin{array}{llllllll}
Q_{i} & M_{i} & S_{i} & T_{i} & Q_{j} & M_{j} & S_{j} & T_{j}
\end{array}\right]^{T},
\end{gathered}
$$

where $v_{i}, v_{j}=$ displacements along the $y$-axis at nodes $i$ and $j ; \theta_{i}, \theta_{j}=$ angle displacements about the $z$-axis at nodes $i$ and $j ; \psi_{i}, \psi_{i}^{\prime}$ and $\psi_{j}, \psi_{j}^{\prime}=$ generalized shear lag DOF at nodes $i$ and $j$, respectively; $Q_{i}, Q_{j}=$ shear forces; $M_{i}, M_{j}=$ bending moments about $z$-axis; $S_{i}, S_{j}$ $=$ shear lag moments corresponding to $\psi_{i}$ and $\psi_{j}$ respectively; $T_{i}, T_{j}=$ shear lag bimoments corresponding to $\psi_{i}^{\prime}$ and $\psi_{j}^{\prime}$, respectively.

The shear lag moment $S$ is a self-existent moment. Generally, shear lag bimoment $T \equiv 0$ if there is no concentrated moment existing at the cross-sections of a box girder.

Based on the variational principle and the governing differential equations including the shear lag effect, a beam element with two shear-lag DOFs at each node has been proposed by the author. The element stiffness matrix could be expressed as [19]

$$
[K]=\left[K_{e}\right]+\left[K_{s}\right] .
$$


In which, $\left[K_{e}\right]=$ elastic stiffness matrix based on elementary beam theory; $\left[K_{s}\right]=$ shearlag-induced stiffness matrix, which is induced by the interaction of bending and shear lag deformation; $[K]=$ element stiffness matrix including effect of shear lag.

The support boundary conditions of box girder corresponding to generalized shear lag displacements are $\psi=0$ while it is fixed, and $\psi^{\prime}=0$ while it is simply supported or free. If there is a concentrated bending moment applied on the beam (for example, the prestressed concrete beams), the new support boundary conditions are $\psi=0$ for a fixed end and $\bar{\psi}=0$ for a simply supported or free end. In which,

$$
\begin{gathered}
\bar{\psi}=\psi^{\prime}-\beta M(x), \\
\beta=\frac{7 n}{6 E I}, n=\frac{1}{1-\left(7 I_{s} / 8 I\right)} .
\end{gathered}
$$

In which, $M(x)=$ bending moment at any section $x$ along the box girder span. $I=$ moment of inertia of the entire cross-section about centroidal axis $z$, and $I_{s}$ is that of flanges $\left(I=I_{w}+I_{s}\right.$, $I_{w}=$ moment of inertia of webs); $E=$ Young's modulus.

The shear lag coefficient can be defined as $\lambda=\sigma_{b} / \bar{\sigma}_{b}$. In which, $\bar{\sigma}_{b}=$ the stress on any section of thin-walled box girder due to bending moment according to the elementary beam theory; $\sigma_{b}=$ the stress due to bending moment including shear lag effect. The shear lag coefficients at the intersection of web and flange $(z=b)$ and at the center of the flange $(z=0)$ are expressed as $\lambda_{w}$ and $\lambda_{c}$, respectively, in following sections.

\section{Construction Process Simulation}

The dynamic finite element method is presented to analyze shear lag effect of box girder in the construction process. It is different from the general structure analysis, where in the actual course of construction, bridge structure system, load status, supported boundary conditions and age of concrete are dynamic with construction process.

The following information is needed to describe the construction process of a bridge: (1) the general information of the structure, (2) construction information, and (3) loading information for the various stages of construction process.

Construction load information in a construction phase refers to new changes of loads on the built structure, such as the dead loads of the new constructed structural members (new additional elements), the changes of basket load, temporary load, shrinkage and creep of concrete, bearing, prestressed or stay cable tension load, and other types of loads.

The structure system as a whole is identified by computer program through the general structure of information. In front of the other information entered, the bridge structure is just a free virtual structure, without stiffness, loads, and distortion. The real structure is generated by the construction information in phase-by-phase simulation. In the simulation of actual construction process, all stage age period, variable value, and differences of shrinkage and creep are considered.

The creep and shrinkage coefficients of concrete are valuated according to Chinese design code [20]. The effective modules method of elasticity is used to calculate the creep forces and deformations. 
Assuming concrete structures acted by long-term loading, after considering the stress changes over time, the strain equation can be expressed as (excluding the effect of shrink of concrete)

$$
\varepsilon(t)=\frac{\sigma\left(\tau_{0}\right)}{E}\left[1+\varphi\left(t, \tau_{0}\right)\right]+\frac{\sigma(t)-\sigma\left(\tau_{0}\right)}{E}\left[1+\varphi\left(t, \tau_{0}\right) \rho\left(t, \tau_{0}\right)\right]
$$

In which, $\varphi\left(t, \tau_{0}\right)=$ creep coefficient of concrete; $\rho\left(t, \tau_{0}\right)=$ age ratio from the loading age $\tau_{0}$ to $t$. For convenience in calculation, the creep coefficient values under the consideration of elasticity-hysteresis effects and its rule over time may be approximately determined by the theory of aging.

$$
\rho\left(t, \tau_{0}\right)=\frac{1}{1-e^{-\rho\left(t, \tau_{0}\right)}}-\frac{1}{\varphi\left(t, \tau_{0}\right)}
$$

The reduction modules of elasticity is defined as

$$
E_{\varphi}=r\left(t, \tau_{0}\right) E
$$

In which, $r\left(t, \tau_{0}\right)=$ effective coefficient.

$$
r\left(t, \tau_{0}\right)=\frac{1}{1+\rho\left(t, \tau_{0}\right) \varphi\left(t, \tau_{0}\right)}
$$

The relationship of the element nodal displacement vector $\{\delta\}$ and element nodal force vector $\{F\}$ after considering creep of concrete can be expressed as

$$
\{F\}=\left[K_{\varphi}\right]\{\delta\},
$$

where

$$
\left[K_{\varphi}\right]=r\left(t, \tau_{0}\right)[K]
$$

$\left[K_{\varphi}\right]=$ element stiffness matrix including effect of shear lag and creep of concrete. The element equivalent nodal force vector due to creep of concrete can be obtained by

$$
\left\{P_{\varphi}\right\}=\left(\left\{P_{q}\right\}-\left\{P_{0}\right\}\right) r\left(t, \tau_{0}\right) \varphi\left(t, \tau_{0}\right)
$$

In which $\left\{P_{q}\right\}=$ external load vector of the element; $\left\{P_{0}\right\}=$ initial force vector existed in the two ends of the element.

In the simulation of actual construction process of a bridge, effects of concrete creep are considered at every stage age period. For the stage $m$ of construction process, the element equivalent nodal force vector due to creep of concrete can be expressed as

$$
\left\{P_{\varphi m}\right\}=\left(\left\{P_{q m}\right\}-\left\{P_{0 m}\right\}\right) r_{m}\left(t, \tau_{0 m}\right) \varphi\left(t, \tau_{0 m}\right)
$$




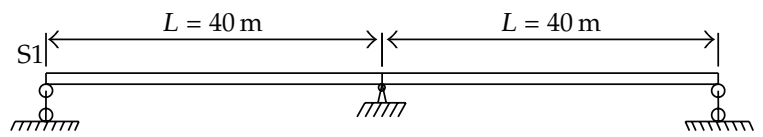

Figure 1: SM continuous beam.

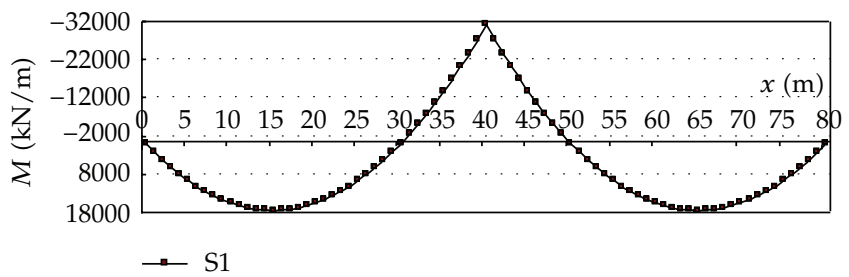

Figure 2: Bending moment of the SM continuous beam.

The shrinkage of concrete also changes over time $t$ but, different from creep, is independence of stress. It is assumed that the law of variation of concrete shrinkage is similar to creep in this paper.

\section{Effect of Construction Process, Prestressing, and Creep}

Generally, from the angle of structural analysis, construction methods of a bridge can be classified as two main types: the construction process without the changes of structural system and that with the changes of structural system. For a simply supported beam bridge, its construction process is simple. The internal forces in a simply supported beam under a certain dead load are unchangeable with construction process and time. But for a longspan bridge the construction process may be very complicated. It can be constructed with or without the changes of structural system. For most of long-span bridges, their construction processes have the changes of structural system. For the case that the construction process has the changes of structural system, the internal forces of a beam under a certain dead load are changeable with construction process and time.

\subsection{Two-Span Continuous Beam with Three Types of Construction Methods}

In the following examples in this section, the effects of construction process and creep of concrete on shear lag of three types of continuous box girder beams are analyzed. The geometry and physical parameters [14] for the continuous box girder beams are as follows: $A=6.225 \mathrm{~m}^{2}, I=8.5578 \mathrm{~m}^{4}, I_{s} / I=0.767, b=2.55 \mathrm{~m}, h=2.75 \mathrm{~m}$ (height of the box girder $h_{0}=$ $3.0 \mathrm{~m}), G / E=0.43, n=3.0407$, and $l=40 \mathrm{~m}$. Furthermore, the reference uniformly distributed dead load $q$ for the continuous box girder beams is assumed to be the self-weight $155.6 \mathrm{kN} / \mathrm{m}$. The creep and shrinkage coefficients are used according to Chinese design code [20]. The long-term effect of creep and shrinkage of concrete is considered to be finished three years late (1100 days is used in following calculations) from the time when the final structural system of a bridge is completed.

The construction methods of a continuous box girder beam can be classified as three typical types: all scaffold method (SM: without the changes of structural system in 


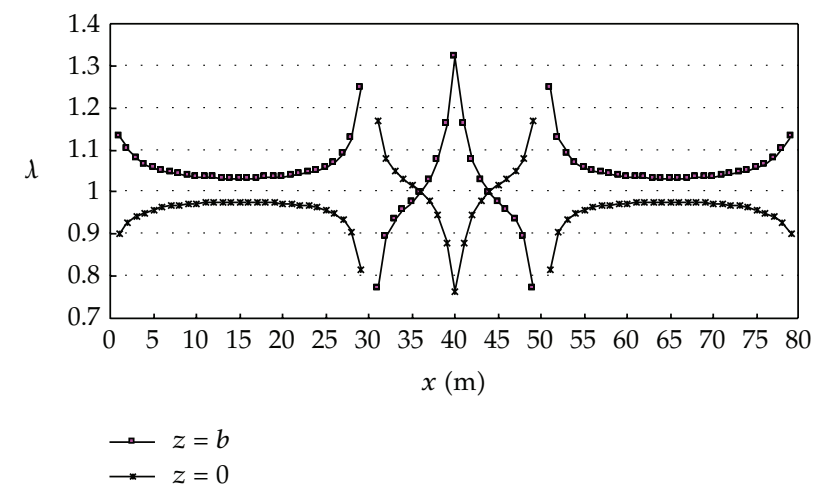

Figure 3: Shear lag coefficients of the SM continuous beam.

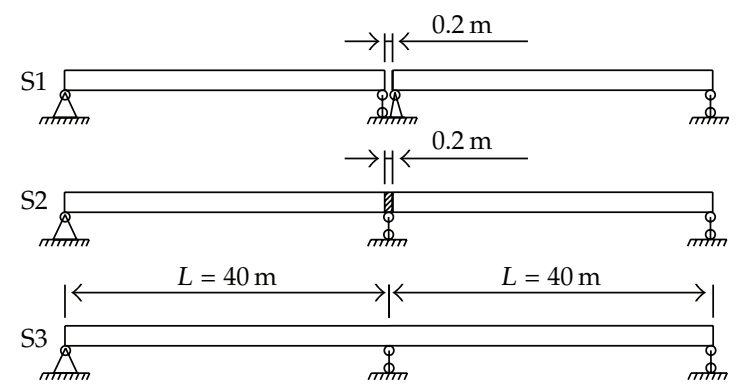

Figure 4: PSSM continuous beam.

construction process), pre-simply-supported method (PSSM: each span is constructed as a simply supported beam at first, then all spans are made "continuous"), and the cantilever method (CM: constructed as cantilevers until they are joined up).

The SM continuous beam (the continuous beam is constructed by using all scaffold method) is shown in Figure 1. The structural system, boundary conditions, and internal forces under self-weight dead load are remaining unchangeable in the construction process of a SM continuous beam. The construction process of a SM continuous beam can be treated as only one step (S1, shown in Figure 1). Figures 2 and 3 show the internal bending moments and shear lag coefficients of the SM continuous beam, respectively.

The PSSM continuous beam (the continuous beam is constructed by using pre-simplysupported method) is shown in Figure 4. The construction process of a PSSM continuous beam can be divided into three main steps (S1, S2, and S3, shown in Figure 4), where the long-term effect of creep and shrinkage of concrete is considered in the last step. The shear lag effects of the PSSM beam are analyzed according to the construction steps. The different structural systems, boundary conditions, and the loading time are considered in the analysis. Figures 5 and 6 show the internal bending moments and shear lag coefficients of the beam in the three steps, respectively.

Figure 7 shows the CM continuous beam (the continuous beam is constructed by using cantilever method). The construction process of a CM continuous beam can be divided into a series of steps (for this beam, 15 steps in total, shown in Figure 7), where the effect of creep 


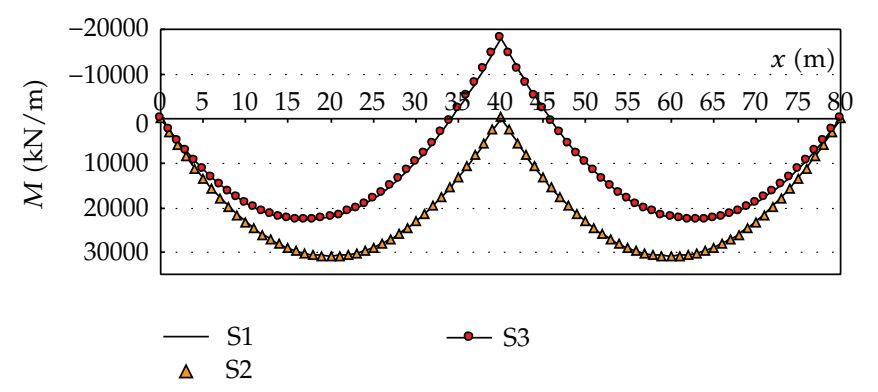

Figure 5: Bending moments of the PSSM continuous beam.

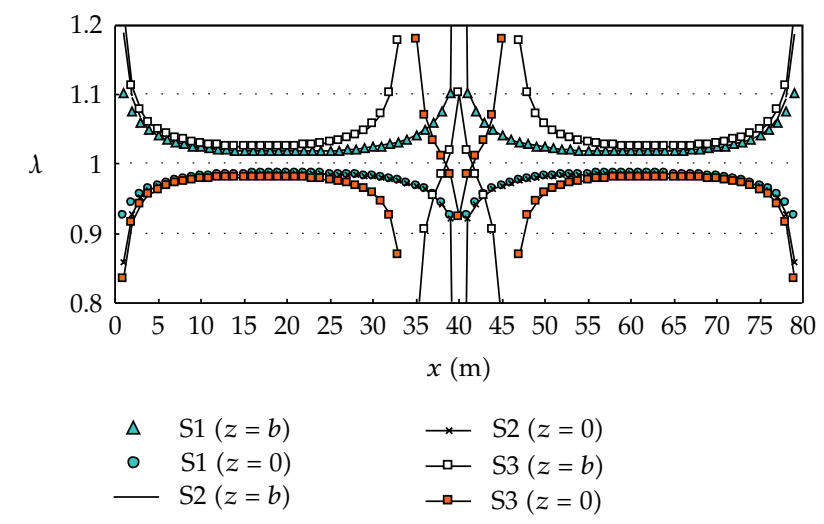

Figure 6: Shear lag coefficients of the PSSM continuous beam.

and shrinkage of concrete on internal forces and shear lag is considered in each step. The longterm effect of creep and shrinkage of concrete is considered in the last step. The construction process of this CM continuous beam can also be simplified as three main steps (S1, S2, and S3, shown in Figure 8). The shear lag effects of the CM continuous beam are analyzed according to the two analytical models shown in Figures 7 and 8 . The different structural systems, boundary conditions, and loading time are also considered in the analysis. Figures 9 and 10 show the internal bending moments and shear lag coefficients of the CM continuous beam, which are calculated according to simplified model (shown in Figure 8). Figure 11 shows the changes of shear lag coefficients at middle-support cross-section of the CM continuous beam with real constructing steps shown in Figure 7.

In addition, to better understand the effect of construction process and creep on shear lag of box girder continuous beam, Table 1 gives comparative results of shear lag coefficients of the above three types of continuous beams in different states of construction process under self-weight.

From Figures 2, 5, and 9 we can see that the bending moments in the same bridge are very different if different construction methods are adopted. Figures 3, 6, 10, 11, and Table 1 show that the shear lag coefficients in different construction stages of a bridge are apparently different. For instance, $\lambda_{w}$ at middle-support section varies from 1.810 to 1.142 for CM beam and varies from 2.382 to 1.102 for PSSM beam. Even at the same cross-sections of a bridge, different shear lag coefficients should be used in different construction stages for the actual design of bridges. 

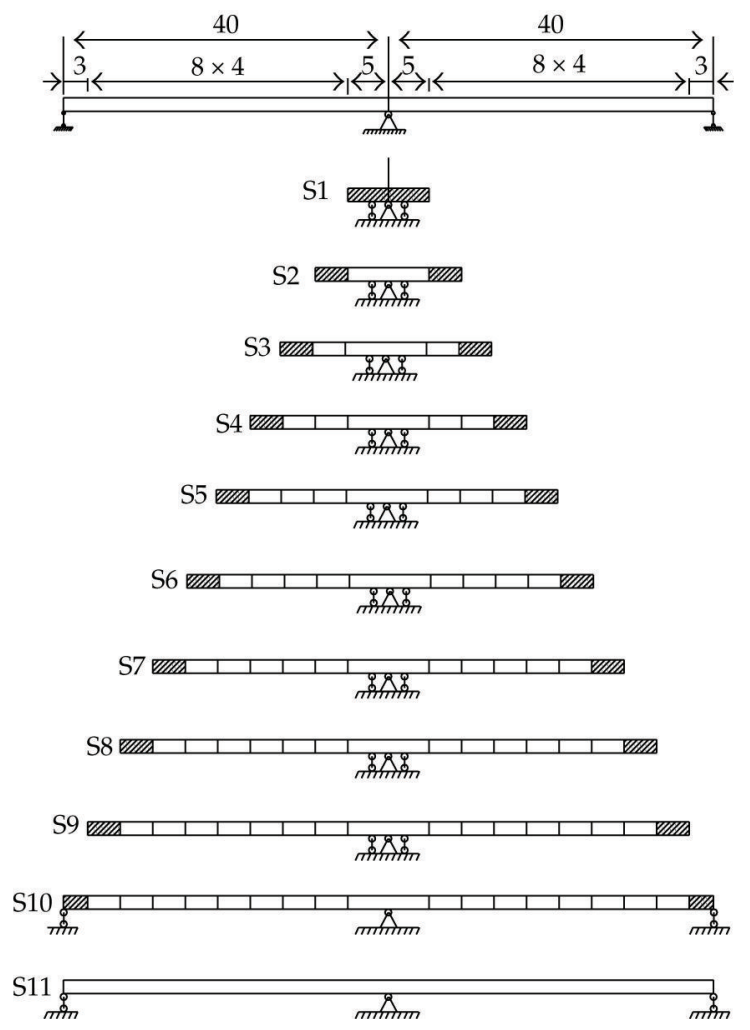

Figure 7: CM continuous beam.
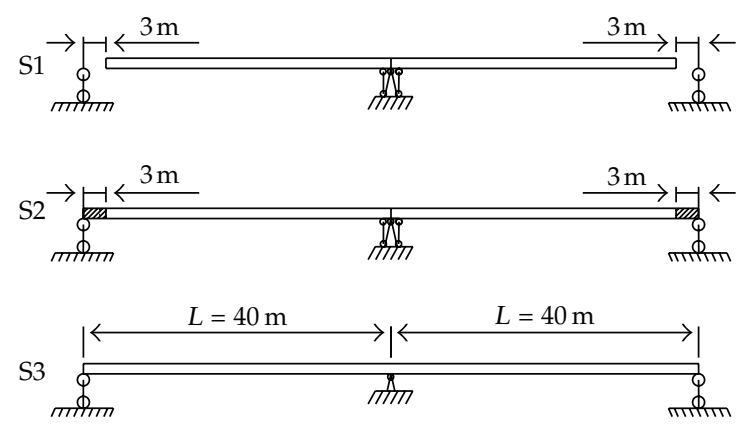

Figure 8: Simplified model of CM continuous beam.

The construction methods have apparent effect on shear lag of box girders. For instance, at the last step of construction, $\lambda_{w}$ at middle-support section for SM, PSSM, and CM beams is $1.322,1.102$, and 1.191 respectively; $\lambda_{w}$ at middle-span section is $1.036,1.026$, and 0.649 , respectively. The shear lag character at middle-span section is positive for SM and PSSM beams, but is negative for CM beam.

The creep of concrete also has a big effect on shear lag of box girders. During the 3 years after being continuous of the CM beam, $\lambda_{w}$ at middle-support section varies from 1.142 


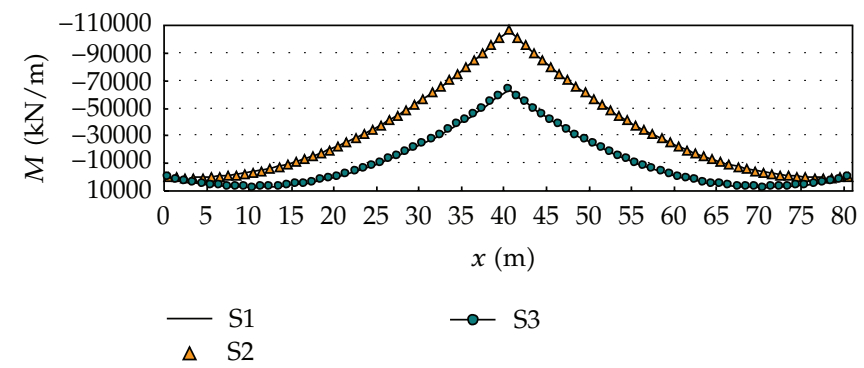

Figure 9: Bending moment of the CM continuous beam by simplified model.

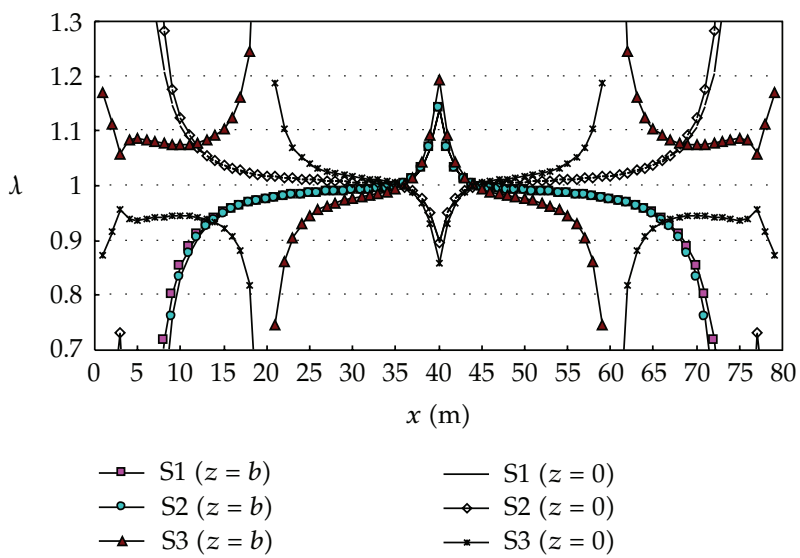

Figure 10: Shear lag coefficients of the CM continuous beam by simplified model.

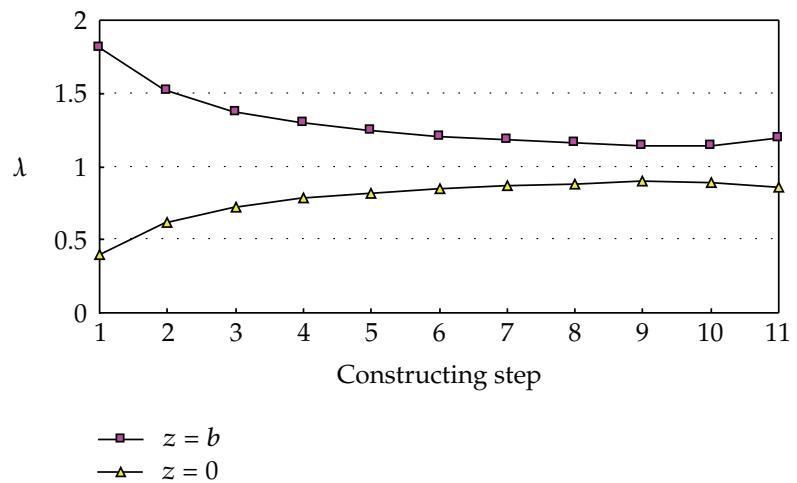

Figure 11: Shear lag coefficients at middle-support cross-section of the $\mathrm{CM}$ continuous beam with real constructing steps.

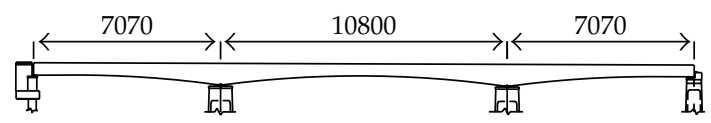

Figure 12: Railway continuous prestressed concrete box girder bridge (unit: $\mathrm{cm}$ ). 
Table 1: Comparison of shear lag coefficients of the continuous beams under self-weight.

\begin{tabular}{|c|c|c|c|c|c|c|c|}
\hline \multirow{2}{*}{ State } & \multirow{2}{*}{ Construction type } & \multirow{2}{*}{ Figure } & \multirow{2}{*}{ Step } & \multicolumn{4}{|c|}{ Shear lag coefficient $\lambda_{w}$ on cross-sections } \\
\hline & & & & $L / 4$ & $L / 2$ & $3 L / 4$ & $L$ \\
\hline \multirow{3}{*}{$\begin{array}{l}\text { Before being } \\
\text { continuous }\end{array}$} & PSSM & Figure 4 & S1 & 1.0245 & 1.0183 & 1.0245 & \\
\hline & CM (simplified model) & Figure 8 & S1 & 0.8528 & 0.9749 & 0.9902 & 1.1409 \\
\hline & $\mathrm{CM}$ & Figure 7 & S9 & 0.8951 & 0.9822 & 0.9930 & 1.1413 \\
\hline \multirow{4}{*}{$\begin{array}{l}\text { After being } \\
\text { continuous }\end{array}$} & SM & Figure 1 & S1 & 1.0362 & 1.0362 & & 1.3218 \\
\hline & PSSM & Figure 4 & S2 & 1.0243 & 1.0183 & 1.0245 & 2.3815 \\
\hline & CM (simplified model) & Figure 8 & S2 & 0.8333 & 0.9747 & 0.9902 & 1.1419 \\
\hline & $\mathrm{CM}$ & Figure 7 & S10 & 0.8812 & 0.9820 & 0.9931 & 1.1420 \\
\hline \multirow{4}{*}{$\begin{array}{l}3 \text { years late after } \\
\text { being continuous }\end{array}$} & SM & Figure 1 & $\mathrm{~S} 1$ & 1.0362 & 1.0362 & & 1.3218 \\
\hline & PSSM & Figure 4 & S3 & 1.0299 & 1.0255 & 1.0573 & 1.1019 \\
\hline & CM (simplified model) & Figure 8 & S3 & 1.0749 & -0.0143 & 0.9770 & 1.1927 \\
\hline & $\mathrm{CM}$ & Figure 7 & $\mathrm{~S} 11$ & 1.0556 & 0.6493 & 0.9842 & 1.1906 \\
\hline
\end{tabular}

to 1.191 and varies from 0.982 to 0.649 at the middle-span section. As for the PSSM beam, $\lambda_{w}$ at middle-support section varies from 2.382 to 1.102 .

\subsection{Three-Span Prestressed Concrete Box-Girder Bridge}

Figure 12 shows a continuous prestressed concrete box girder bridge. It is an actual railway prestressed concrete bridge in China. Figure 13 shows the longitudinal distributions of prestressing in half of the girder and distributions of prestressing on cross-sections. The bridge is constructed using the cantilever method $(\mathrm{CM})$. For the prestressed continuous box girder, the internal forces and the effect of shear lag are analyzed according to the actual construction process. The changes of structural system (including the support-boundary conditions), the shrinkage and creep of concrete, the prestress loses, and secondary dead loads are all considered in the calculations. It is noted that the theoretical bending moment calculated according to actual construction process is adopted. In addition, for convenience of the analysis, some simplification is used in the calculations of geometry parameters of cross-sections.

To investigate the effect of construction progress, creep of concrete, and prestressing on shear lag of the continuous box girder, the following five cases are considered.

Case 1. The internal forces and shear lag effect are analyzed by assuming that the continuous bridge is constructed using the all scaffold method (SM), and that the prestressing is not considered. In this case, the construction process, the changes of structural system, prestressing, and creep are not included in the calculations. Figure 14 shows the longitudinal distribution of shear lag coefficients in half of the bridge at last stage in this case.

Case 2. The internal forces and shear lag effect are analyzed according to actual construction process (the bridge is constructed by using the $\mathrm{CM}$ ), but the prestressing and creep are not considered. In this case, the construction process and the changes of structural system are included in the calculations but the prestressing and the creep of concrete are not. Figure 15 


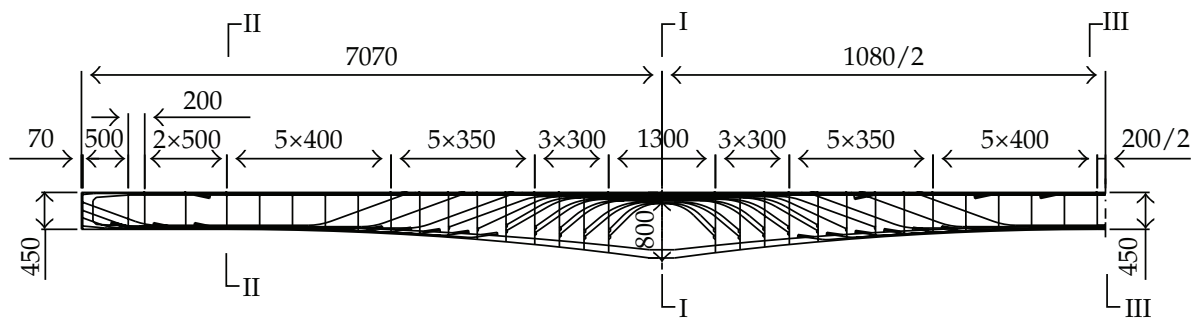

(a)

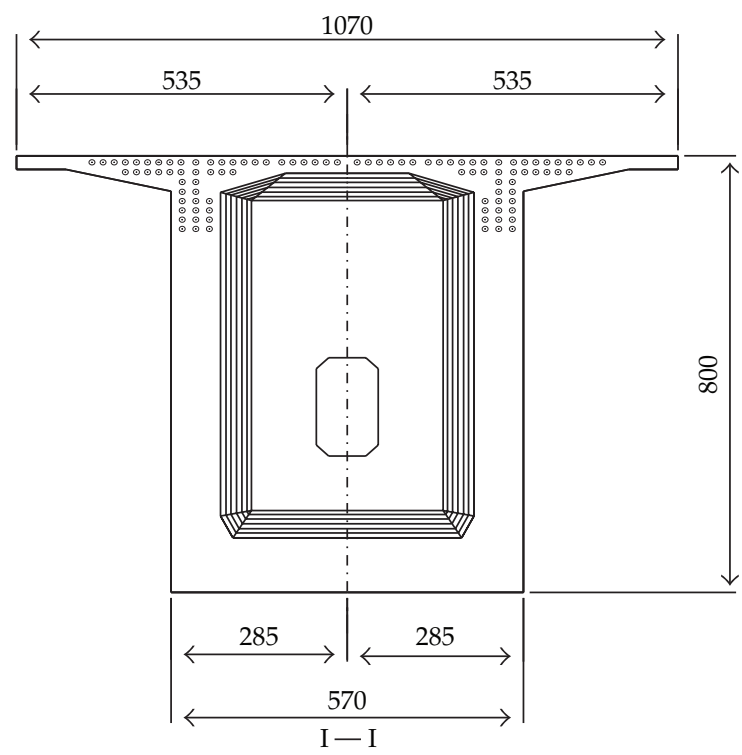

(b)

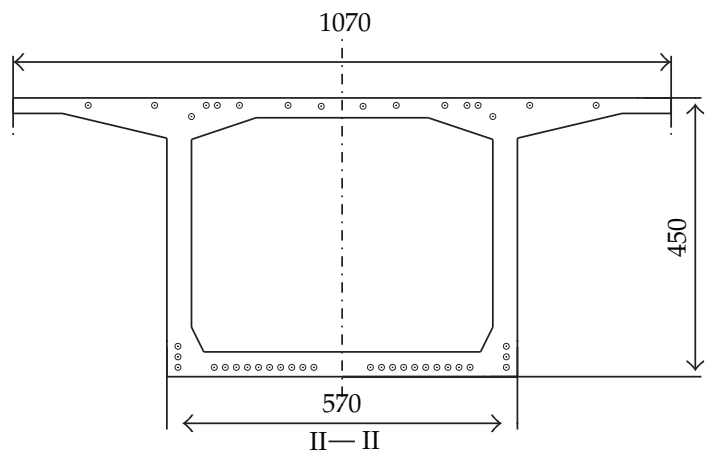

(c)

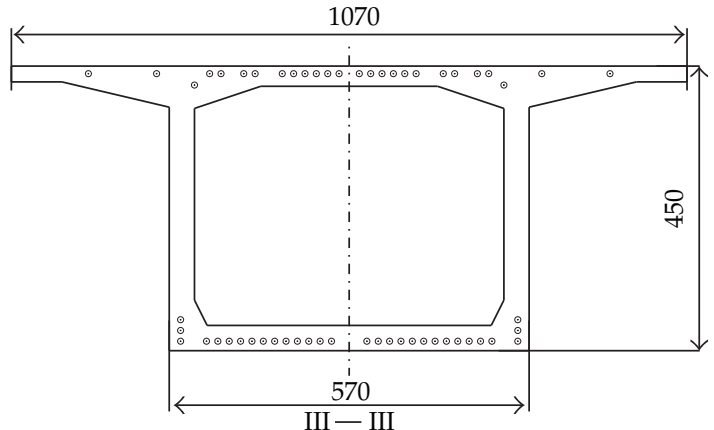

(d)

Figure 13: Prestressing distributions in the railway bridge (unit: $\mathrm{cm}$ ). 


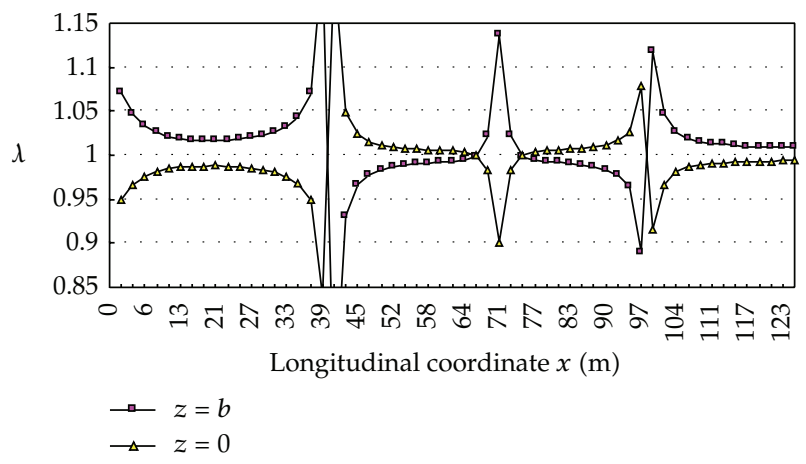

Figure 14: Shear lag coefficients in half of the bridge based on SM (excluding prestressing and creep).

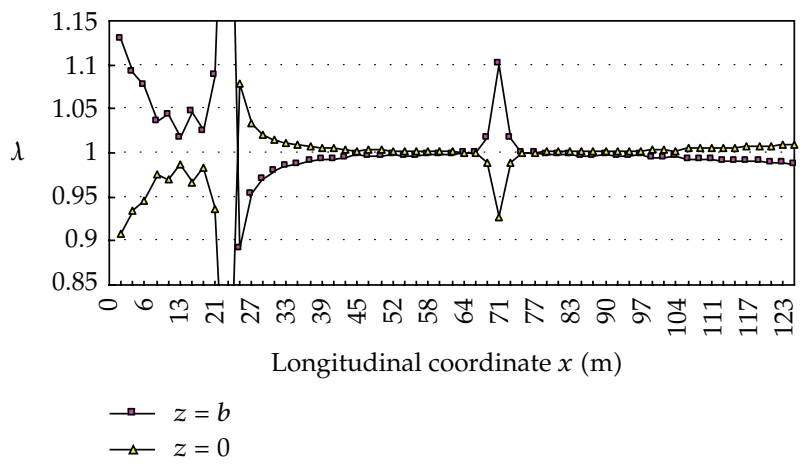

Figure 15: Shear lag coefficients in half of the bridge based on CM (excluding prestressing and creep).

shows the longitudinal distribution of shear lag coefficients in half of the bridge at last stage in this case.

Case 3. The internal forces and shear lag effect are analyzed according to actual construction process, but the prestressing is not considered. Except the prestressing, the construction process, the changes of structural system, and creep of concrete are all included in the calculations. Figure 16 shows the longitudinal distribution of shear lag coefficients in half of the bridge at last stage in this case.

Case 4. The internal forces and shear lag effect are analyzed according to actual construction process, but creep of concrete is not considered. Except creep of concrete, the construction process, the changes of structural system, and the prestressing are all included in the calculations. Figure 17 shows the longitudinal distribution of shear lag coefficients in half of the bridge at last stage in this case.

Case 5. The internal forces and shear lag effect are analyzed according to actual construction process. The construction process, the changes of structural system, the prestressing, and creep are all included in the calculations. Figure 18 shows the longitudinal distribution of shear lag coefficients in half of the bridge at last stage in this case. 


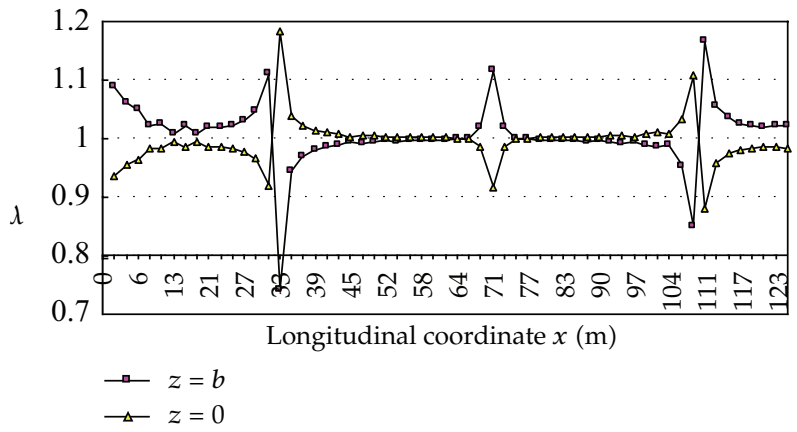

Figure 16: Shear lag coefficients in half of the bridge based on CM (including creep but not prestressing).

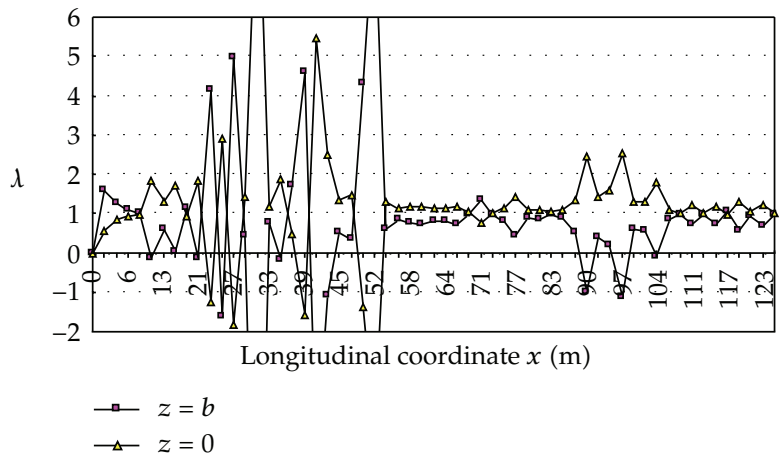

Figure 17: Shear lag coefficients in half of the bridge based on CM (including prestressing but not creep).

To further observe the shear lag effect on the box girder beam, the stresses at the intersection of web and flange $(z=b)$ and at the center of the flange $(z=0)$ on the top and bottom slabs of the cross-sections are calculated for cases 4 and 5 . The results are shown in Figures 19 and 20.

By comparing Figure 14 with Figure 15, or Figure 14 with Figure 18, it shows that shear lag coefficients for the same bridge are obviously different by using SM and CM construction methods. The construction methods and construction process have big effects on shear lag of the continuous concrete box beam. Comparison of Figure 15 with Figure 16 and Figure 17 with Figure 18 shows that the creep of concrete has obvious effect on shear lag of the continuous concrete box beam. By Comparing Figure 15 with Figure 17 and Figure 18, it shows that the prestressing has significant effect on shear lag of the continuous concrete box beam. The effect of the prestressing on shear lag of box beams is more apparent than vertical distributed and concentrated loads.

Figures 17 and 18 also show that the values and distributions of shear lag coefficients are related to the anchorage locations and the distributions of internal forces along the girder under the combination of all types of loads, including ones of prestressing and creep of concrete. The negative shear lag may occur at any cross-sections due to prestressing. The maximum value of shear lag coefficient $\lambda_{w}$ of box beams generally occurs where the prestressed tendons are anchored.

Figures 19 and 20 show that the effect of shear lag should not be ignored in actual design of box girder bridges due to its significance on the stresses of a cross-section. 


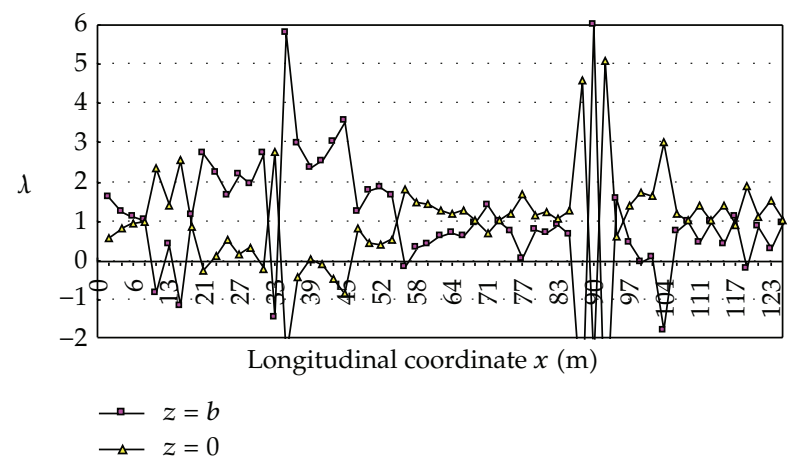

Figure 18: Shear lag coefficients in half of the bridge based on CM (including prestressing and creep).

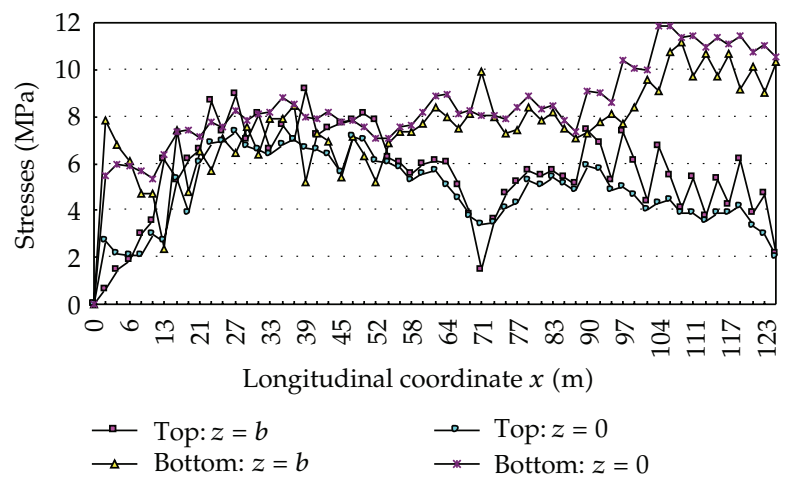

Figure 19: Stresses in half of the bridge based on CM (including prestressing but not creep).

\section{Conclusions}

A FEM based on the variational principle is developed to analyze the effect of construction process and creep of concrete on shear lag of concrete box girder bridges. The shear lag effects of three types of continuous concrete beams are analyzed in detail according to construction process. An actual prestressed concrete box girder bridge is also analyzed according to the actual construction process. The changes of structural system with the construction process, the changes of loading and boundary conditions with the construction process and time, the prestressing, and creep are all imitated in the calculations. The main conclusions made in this study are as follows:

(i) The internal forces in a same bridge are very different if the different construction methods are adopted. The creep of concrete has very big influence on the internal forces for the bridges using different construction methods.

(ii) The shear lag coefficients in different construction stages of a bridge are apparently different. At the same cross-sections of a bridge the different shear lag coefficients should be used in different construction stages for the actual design of bridges.

(iii) The construction methods, the construction process, the prestressing, and creep of concrete have apparent effect on shear lag of the continuous concrete box beams. 


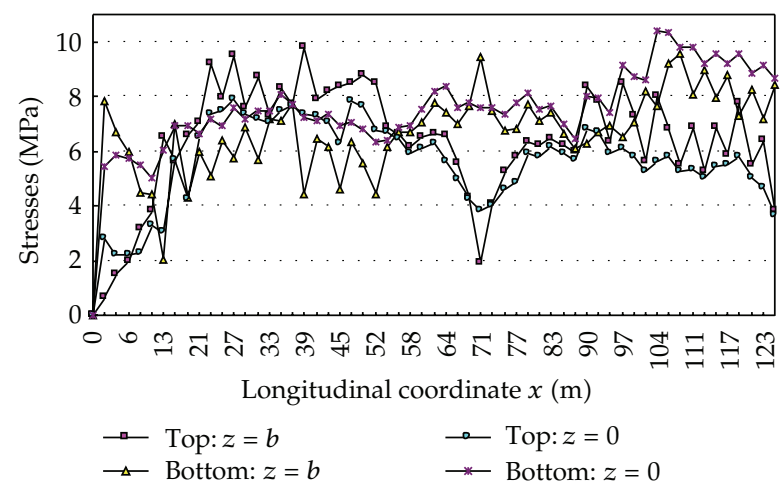

Figure 20: Stresses in half of the bridge based on CM (including prestressing and creep).

(iv) The effect of prestressing on shear lag of box beams is more apparent than vertical distributed and concentrated loads.

(v) The effect of shear lag on the stresses of cross-section is significant and cannot be neglected in actual design of box girder bridges.

\section{Notation}

$b$ : $\quad$ Half the clear width of the box section

E: $\quad$ Young's module

$E_{\varphi}: \quad$ Reduction module of elasticity

$\{F\}: \quad$ Element nodal force vector

$h_{i}$ : $\quad$ Distance between centroid of cross-section and the midplane of the $i$ th flange

I: $\quad$ Moment of inertia of the whole section about centroidal axis

$I_{s}$ : $\quad$ Moment of inertia of flanges with respect to the centroid of the box section

$k$ : $\quad$ Reissner's parameter, $k=(1 / b) \sqrt{(14 G n / 5 E)}$

$\left[K_{e}\right]: \quad$ Elastic stiffness matrix

$\left[K_{s}\right]$ : Shear-lag-induced stiffness matrix

$[K]: \quad$ Element stiffness matrix including effect of shear lag

$\left[K_{\varphi}\right]$ : Element stiffness matrix including effect of shear lag and creep of concrete

$l: \quad$ Length of element or beam span

$M(x)$ : Bending moment at any section $x$ along the box girder

$n: \quad$ Reissner's parameter, $n=1 /\left(1-\left(7 I_{s} / 8 I\right)\right)$

$\left\{P_{q}\right\}:$ Element equivalent nodal force vector induced by external loads

$\left\{P_{0}\right\}:$ Initial force vector existed in the two ends of the element

$\left\{P_{\varphi}\right\}$ : Element equivalent nodal force vector considering creep of concrete

$Q(x)$ : Shear force at any section $x$ along the box girder

$q$ : $\quad$ vertical distributed load

$r\left(t, \tau_{0}\right)$ : Effective coefficient

$S: \quad$ Shear lag moment

$T$ : $\quad$ Shear lag bimoment 


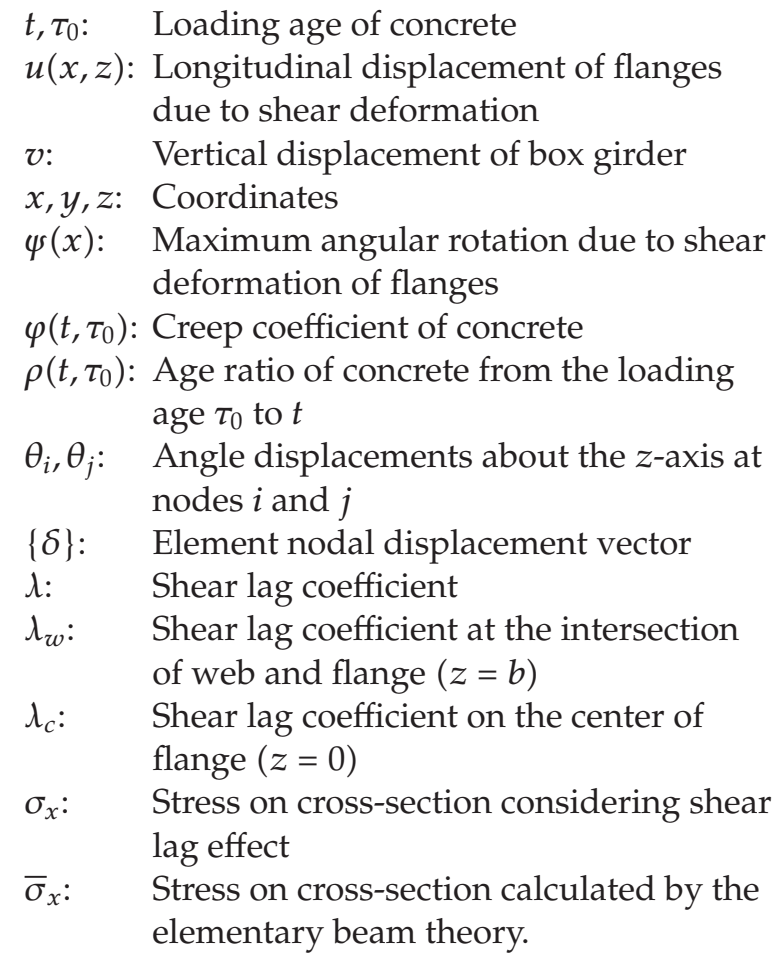

\section{References}

[1] A. DeFries-Skene and A. C. Scordelis, "Direct stiffness solution for folded plates," Journal of the Structural Division, vol. 90, no. 4, pp. 15-48, 1964.

[2] V. Kristek, "Folded plate approach to analysis of shear wall systems and frame structures," Proceedings of the Institution of Civil Engineers, vol. 67, no. 2, pp. 1065-1075, 1979.

[3] Q. G. Song and A. C. Scordelis, "Formulas for shear-lag effect of T-, I- and box beams," Journal of Structural Engineering, vol. 116, no. 5, pp. 1306-1318, 1990.

[4] H. R. Evans and A. R. Taherian, "The prediction of the shear lag effect in box girders," Proceedings of the Institution of Civil Engineers, vol. 63, no. 2, pp. 69-92, 1977.

[5] A. R. Taherian and H. R. Evans, "The bar simulation method for the calculation of shear lag in multicell and continuous box girders," Proceedings-Institution of Civil Engineers, vol. 63, no. 2, pp. 881-897, 1977.

[6] A. K. H. Kwan, "Shear lag in shear/core walls," Journal of Structural Engineering, vol. 122, no. 9, pp. 1097-1104, 1996.

[7] S. C. Lee, C. H. Yoo, and D. Y. Yoon, "Analysis of shear lag anomaly in box girders," Journal of Structural Engineering, vol. 128, no. 11, pp. 1379-1386, 2002.

[8] Q. Z. Luo, Q. S. Li, and J. Tang, "Shear lag in box girder bridges," Journal of Bridge Engineering, vol. 7, no. 5, pp. 308-312, 2002.

[9] Q. Z. Luo, J. Tang, and Q.S. Li, "Finite segment method for shear lag analysis of cable-stayed bridges," Journal of Structural Engineering, vol. 128, no. 12, pp. 1617-1622, 2002.

[10] E. Reissner, "Analysis of shear lag in box beams by the principle of minimum potential energy," Quarterly of Applied Mathematics, vol. 5, no. 3, pp. 268-278, 1946.

[11] S. T. Chang, "Prestress influence on shear-lag effect in continuous box-girder bridge," Journal of Structural Engineering, vol. 118, no. 11, pp. 3113-3121, 1992.

[12] S. T. Chang, "Shear lag effect in simply supported prestressed concrete box girder," Journal of Bridge Engineering, vol. 9, no. 2, pp. 178-184, 2004.

[13] S. T. Chang and F. Z. Zheng, "Negative shear lag in cantilever box girder with constant depth," Journal of Structural Engineering, vol. 113, no. 1, pp. 20-35, 1987. 
[14] S. T. Chang and F. Z. Zheng, Shear Lag Effect of Thin-Walled Box Girders, Communications Press, Beijing, China, 1998.

[15] J. Q. Guo, J. Lian, A. Glassrnan et al., "Analysis of shear lag effect in box girder bridge," China Civil Engineering Journal, vol. 16, no. 1, pp. 1-13, 1983 (Chinese).

[16] Y. Wu, S. Liu, Y. Zhu, and Y. Lai, "Matrix analysis of shear lag and shear deformation in thin-walled box beams," Journal of Engineering Mechanics, vol. 129, no. 8, pp. 944-950, 2003.

[17] S. J. Zhou, "Shear lag analysis of box girders," Gongcheng Lixue/Engineering Mechanics, vol. 25, no. 2, pp. 204-208, 2008 (Chinese).

[18] S. J. Zhou, "Shear lag analysis in prestressed concrete box girders," Journal of Bridge Engineering, vol. 16, no. 4, pp. 500-512, 2011.

[19] S. J. Zhou, "A finite beam element considering shear lag effect in box girder," Journal of Engineering Mechanics-ASCE, vol. 136, no. 9, pp. 1115-1122, 2010.

[20] Minister of China Communications, Code for Design of Highway Reinforced Concrete and Prestressed Concrete Bridges and Culverts, Communications Press, Beijing, China, 2004. 


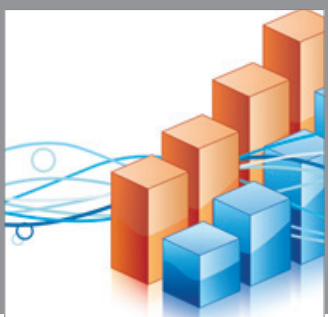

Advances in

Operations Research

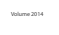

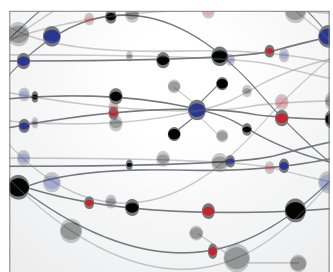

\section{The Scientific} World Journal
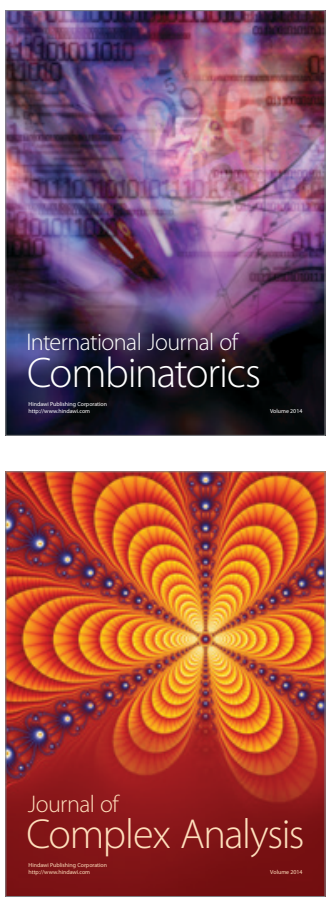

International Journal of

Mathematics and

Mathematical

Sciences
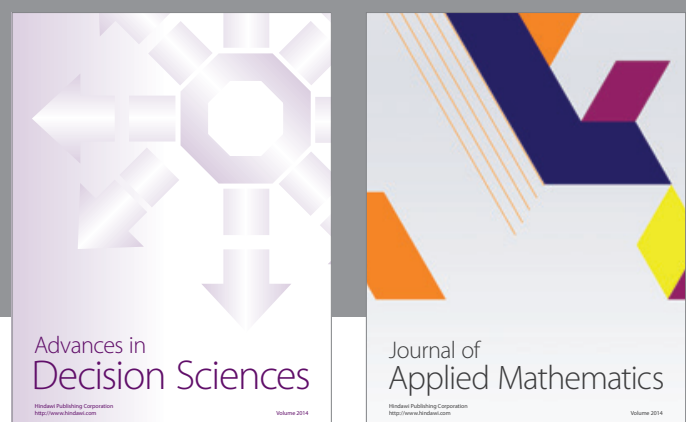

Journal of

Applied Mathematics
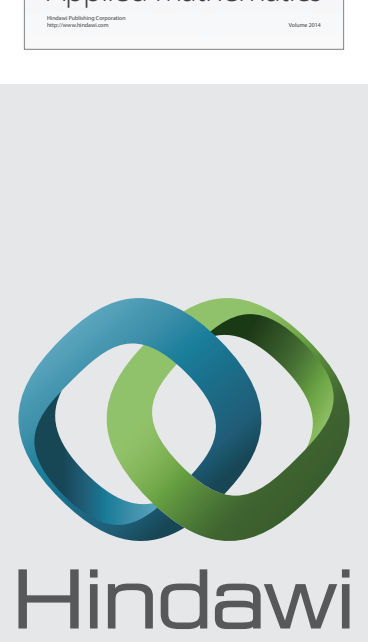

Submit your manuscripts at http://www.hindawi.com
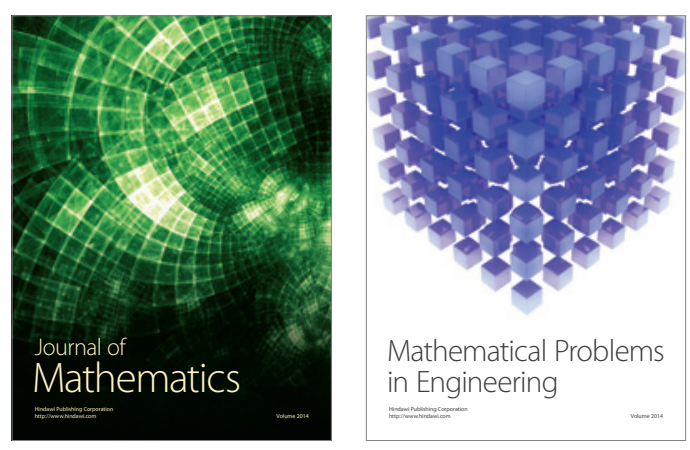

Mathematical Problems in Engineering
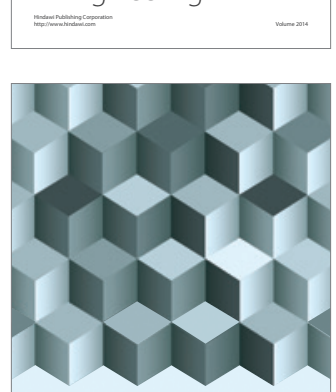

Journal of

Function Spaces
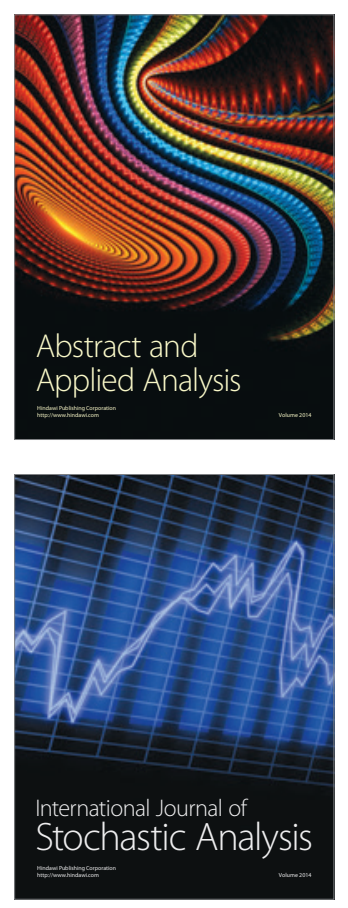

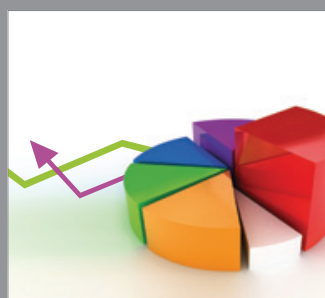

ournal of

Probability and Statistics

Promensencen
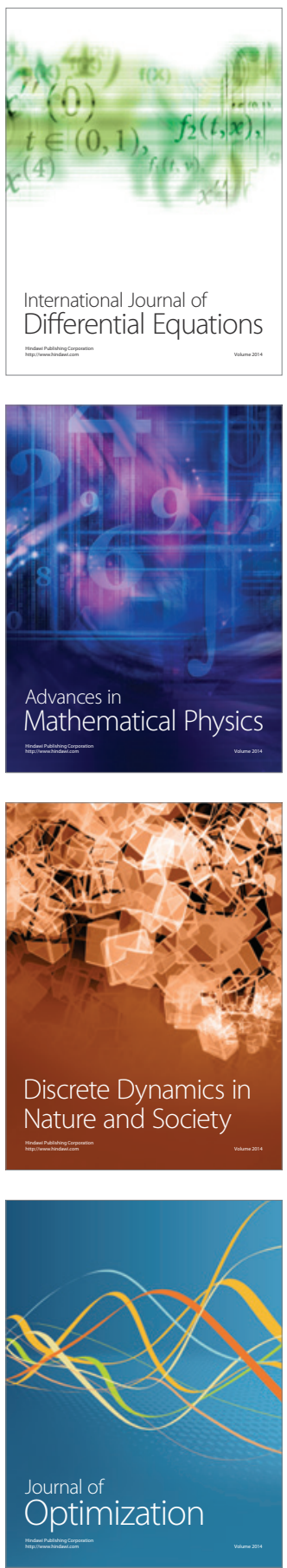